\title{
JURISPRUDENCIA CONSTITUCIONAL
}

POR EL

DEPARTAMENTO DE DERECHO ADMINISTRATIVO DE LA UNED *

\section{SUMARIO}

I. Indice--II. Autonomía--III. Constitución económica--IV. Enseñanza.-V. Función pública.-VI. Indefensión.-VII. Legitimación.-VIII. Libertades de expresión, reunión y manifestación: Límites.-IX. Régimen electoral general.

\section{I}

\section{INDICE}

1. INDICE CRONOLOGICO DE SENTENCIAS DEL TRIBUNAL CONSTITUCIONAL

Publicación en «BOE» 1982

1. Sentencia de 16 de diciembre de 1981. Recurso de amparo núm. 215/1981. Sala Segunda. Ponente: F. Rubio Llorente $(B O E, 14$ de enero de 1982, suplemento al núm. 12). Artículo que se infringe según el recurrente: 24 de la Constitución.

Desestima el amparo

\section{Indefensión}

No se considera infringido el artículo 24.1 , que no dispensa en modo alguno de proceder con diligencia necesaria para realizar en tiempo hábil las actuaciones que a su derecho convengan.

* El profesor T. R. Fernández Rodríguez, que dirige el Departamento de Derecho Administrativo de la UNED, coordina la elaboración del contenido de esta sección. La redacción de los epígrafes que constan en el sumario ha sido realizada por los siguientes profesores: I: E. Linde; II: I. Astarloa; III: C. Vila; IV: J: Prieto; V: C. Vila; VI: A. Serrano; VII: E. Linde; VIII: E. Gómez Reino; IX: C. Vila. 
2. Sentencia de 18 de diciembre de 1981. Recurso de inconstitucionalidad número 208/1981. Pleno. Ponente: A. Truyol Serra (BOE, 14 de enero de 1982, suplemento al núm. 12). Artículos aludidos por el recurrente: $9.3 ; 66.1 ; 67.2$; $69.1,2,5$ y $6 ; 70.1 ; 81$ y 161.2 de la Constitución. Otros artículos de la Constitución citados en la sentencia: $1.2 ; 70.2$.

Presidente del Gobierno

\section{Contra}

Ley del Parlamento Vasco 4/1981, de 18 de marzo, sobre «designación de senadores representantes de Euskadi».

\section{Fallo}

Desestima el recurso, debiendo corregirse los errores materiales cometidos al transcribirse las letras a) a f) del artículo 70.1 de la Constitución en el artículo 2.2 de la Ley impugnada.

3. Sentencia de 18 de diciembre de 1981. Recursos de amparo núms. 55,56 y 57/1981. Pleno. Ponente: L. Díez Picazo (BOE, 14 de enero de 1982, suplemento al núm. 12). Artículo que se infringe según el recurrente: 24 de la Constitución. Otros artículos de la Constitución citados en la sentencia: 14 a 30.

Desestima el amparo

Derecbo a la tutela jurisdiccional

Tutela efectiva de jueces y Tribunales

El hecho de que el procedimiento de ejecución sumario se caracterice por la ausencia de contradicción procesal, en consonancia con la naturaleza del título (Ley de Enjuiciamiento Civil, artículo 1.560; Decreto-ley de 5 de febrero de 1869, y los artículos 33, 34 y 35 de la Ley de 2 de diciembre de 1872), no significa que sea inconstitucional por contrario al artículo 24 del texto fundamental.

4. Sentencia de 22 de diciembre de 1981. Recurso de inconstitucionalidad número 221/1981. Pleno. Ponente: R. Gómez-Ferrer Morant (BOE, 14 de enero de 1982, suplemento del núm. 12). Artículos que se infringen según el recurrente: $9.3 ; 23 ; 103.3 ; 149.1 .18 .^{a}$ y $30 .^{a}$ de la Constitución. Otros artículos de la Constitución citados en la sentencia: 14 ; título $I$; 23.2 ; 53.1 ; 137 ; 149.1.1; $150.3 ; 155.1$.

Principio de igualdad en el acceso a la función pública

Régimen jurídico de las Administraciones públicas

Títulos académicos

Presidente del Gobierno

\section{Contra}

Artículo 13.2 y disposición transitoria segunda, apartado $10^{\circ}$, de la Ley de la Generalidad de Cataluña núm. 3/1981, de 22 de abril, sobre Bibliotecas. 


\section{Fallo}

Declata la inconstitucionalidad y consiguiente nulidad del artículo 13.2 y de la disposición transitoria segunda, número uno, de la Ley de la Generalidad de Cataluña núm. 3/1981, de 22 de abril, sobre Bibliotecas, publicada en el Diario Oficial número 123 , de 29 de abril de 1981 .

Voto particular del magistrado M. Díez de Velasco, al que se adhiere el magistrado L. Díez Picazo.

5. Sentencia de 28 de enero de 1982 (núm. 1/1982). Conflictos positivos de competencia núms. 63 y 191/1981 (acumulados). Ponente: F. Tomás y Valiente ( $B O E, 26$ de febrero de 1982, suplemento al núm. 49). Artículos que se infringen según el Gobierno vasco: 149.1.11. a y 13.a, y 149.3 de la Constitución. Artículos que se infringen según el Gobierno español: 13; 18; 133.4; 142; 149.1.11. ${ }^{\mathrm{a}}$ de la Constitución. Otros artículos de la Constitución citados en la sentencia: $1.1 ; 2 ; 40.1 ; 82 ; 83 ; 128.1 ; 130.1 ; 131.1 ; 133.4 ; 138.1$ y 2 ; $139.2 ; 149.10 .^{\mathrm{a}}, 14 .^{\mathrm{a}}$ y $18 .^{\mathrm{a}} ; 150.1 ; 156.1 ; 161.2$.

Cajas de Aborro

\section{Gobierno vasco}

En relación con el Real Decreto 2.869/1980, de 30 de diciembre, «por el que se establecen las condiciones y el orden de prioridad para la computabilidad de los valores de renta fija emitidos directamente o calificados por las Comunidades Autónomas en el coeficiente de fondos públicos de las Cajas de Ahorro».

\section{Gobierno español}

frente al Decreto del Gobierno vasco 45/81, de 16 de marzo, «sobre régimen de dependencia de las Cajas de Ahorro de la Comunidad Autónoma del País Vasco».

\section{Fallo}

1. Declarar que 1a titularidad de las competencias controvertidas respecto al Real Decreto $2.869 / 1980$, de 30 de diciembre; corresponde al Gobierno de la nación, por lo que no procede anular ninguno de los preceptos impugnados por el Gobierno vasco.

2. Declarar que la titularidad de las competencias controvertidas respecto a los artículos 2; 3.2 (incisos «y de todos los miembros de sus distintos ótganos de gobierno» $\mathrm{y}$ «sin perjuicio de que aquel departamento haga seguir tales informaciones al Banco de España»); 3.3; 6.4; 6.5; 6.6 y 10 del Decreto 45/1981, de 16 de marzo, del Gobierno vasco corresponden a éste.

3. Declarar que la titularidad de las competencias controvertidas respecto a los artículos 5, a); 5, b), y 7.1, a), del citado Decreto 45/1981, de 16 de marzo, del Gobierno vasco corresponden a éste siempre que tales normas se interpreten en los términos contenidos en los fundamentos correspondientes de esta sentencia. 
4. Declarar que la titularidad de las competencias ejercidas en los artículos 4, b) y 6.3 del Decreto 45/1981, de 16 de marzo, del Gobierno vasco corresponden al Estado, por lo que se acuerda anular los dos citados preceptos y, por remisión al primero de ellos, el inciso del artículo primero, que dice: «con excepción de lo prevenido en el apartado b) del artículo cuarto».

\section{AUTONOMIA}

El Tribunal Constitucional ha tenido nuevamente ocasión, en el períado considerado, de precisar cuestiones básicas en materia autonómica. Y lo ha hecho, en la misma línea anterior, de forma cuantitativa y cualitativamente amplia, en cuanto que los fallos sobre recursos planteados sobre el tema han sido una vez más varios e importantes. Procede, por tanto, insistir de entrada en la constatación de que el cambio territorial del Estado abierto por la Constitución sigue ocupando parte decisiva de la tarea del Alto Tribunal desde su entrada en funcionamiento.

Como es de suponer, en esta reseña vuelven a aparecer clarificaciones sobre conceptos que el Tribunal, en atención a los mandatos constitucionales, ha ido destacando como parámetros fundamentales de enjuiciamiento. Así: la idea de interés general, las llamadas competencias exclusivas, la determinación de las normas atributivas de competencia, la.delimitación material de legislación básica, la incidencia del principio de igualdad, etc. Especial referencia merece en este marco introductorio la constatación de la aceptación por el Tribunal (y utilización) del fructífero concepto del «bloque de la constitucionalidad», y no sólo en referencia directa a lo dispuesto en el artículo 28 de su propia Ley Orgánica, sino en su acepción y consideración más general (sentencia 10/82, de 23 de marzo).

A tenor de todo ello encontramos de nuevo en las sentencias consideradas el tratamiento de problemas ya conocidos, en cuanto afrontados en litigios anteriores. Destacaremos aquí, en breve listado, la solución aportada al caso de concurrencia de intereses generales, que el Tribunal vincula (aunque no de forma unánime) al estudio del «contenido inherente» de las respectivas competencias sobre la materia concurrida; la reiteración sobre la necesidad de una lectura material de la legislación básica del Estado, y los criterios aportados para la delimitación del ámbito territorial de las competencias estatutarias. Junto a ello, y como precisiones más llamativas: la exigencia de estabilidad del cuadro estatal de base, la innecesariedad de que las normas de las Comunidades repitan de forma superflua bases o disposiciones del Estado y la concreción de los términos específicos en que debe entenderse la competencia estatutaria de «desarrollo legislativo y ejecución».

En este marco, hacer balance no resulta especialmente complicado. Resalta por sí misma una consideración de la mayor trascendencia: el Tribunal Constitucional viene progresiva y reiteradamente asentando un cuerpo doctrinal de utilización indispensable para una interpretación cada vez más coherente del título VIII de la Constitución y para un trazado armónico y sin desviaciones del proceso autonómico en marcha. El propio Tribunal recuerda continuamente la suma de complejidades que rodean a la cuestión, lo que hace frecuentemente debatibles las soluciones al caso concreto; pero bueno es que, a tres años de la puesta en marcha del tren de las autonomías, dispongamos ya de unas vías de encauzamiento principales desde las que descender luego a la solución específica de cada una de las controversias.

Es desde esos criterios generales que el propio Tribunal está resolviendo, cada 
vez con mayor agilidad, los temas concretos. Lo podemos constatar ahora en base a las dos sentencias más interesantes del período: la que resuelve el recurso sobre el Consejo Asesor de RTVE en Cataluña y la solución al conflicto sobre las Cajas de Ahorro en el País Vasco. Ante esa dualidad del contenido de las declaraciones del Tribunal Constitucional (conceptos generales-soluciones puntuales) sistematizamos la reseña en base a cuatro grandes grupos de imputación que inmediatamente desarrollamos:

1) Delimitación de competencias.

2) Legislación básica.

3) Distribución de competencias económicas.

4) Competencias autonómicas en materia de radio y televisión.

\section{A) DELIMITACION DE COMPETENCIAS}

1. La distribución de competencias realizada por la Constitución admite la coincidencia sobre una misma materia de intereses generales de diverso alcance. Para distribuir los distintos campos debe estudiarse primero el contenido inberente a cada competencia.

(Sentencia de 22 de diciembre de 1981; recurso 221/1981 contra Ley de la Generalidad 3/1981, de 22 de abril, sobre Bibliotecas. En voto particular, los magistrados Díez de Velasco y Díez Picazo hacen prevalecer el principio formal del «carácter exclusivo».)

«La Constitución distingue entre distintos niveles de interés general, en función de los cuales han de atribuirse las respectivas competencias (artículos 150.3, 155.1 y 137, entre otros). En concreto, la consecución del interés general de la nación en cuanto tal y de las de carácter supracomunitario queda confiada a los órganos generales del Estado, lo que se traduce en la atribución al mismo de una serie de competencias, entre las cuales se encuentran las del artículo 149.1 de la Constitución, y, por otra parte, el interés general propio de cada comunidad se refleja asimismo en la asunción de una serie de competencias en su respectivo Estatuto.

La técnica utilizada por la Constitución es compleja, dada la coincidencia sobre una misma materia de intereses generales de diverso alcance y dado que un mismo objeto es susceptible - generalmente- de ser situado en diversos campos. De aquí que para solucionar las cuestiones que puedan plantearse hay que partir del contenido inherente a cada competencia, y sólo si, aun aplicando este criterio, se sigue produciendo un entrecruzamiento habrá que determinar la competencia que debe prevalecer.»

(En este recurso, la exigencia al personal técnico bibliotecario de titulación en la Escola de Bibliología de Barcelona o las que pueda determinar el Govern de la Generalitat «han de incluirse en el contenido inherente de la competencia reservada al Estado por el artículo 149.1.30 de la Constitución».

Infringe también esta exigencia el principio de igualdad, pues «el título correspondiente a cada nivel educativo, a cada ciclo, en su caso a cada especialidad, ha de tener el mismo valor en toda España y, desde una perspectiva legal, no se puede valorar desigualmente el acreditativo de haber cursado los estudios en cada Centro - por ejemplo, licenciado en Derecho 
por tal o cual Facultad-. Todos los títulos obtenidos en cada nivel, ciclo o especialidad tienen el mismo valor, y no se puede tratar desigualmente a los ciudadanos en función de la Escuela en la que han obtenido su título, porque tal desigualdad no tiene justificación razonable alguna.)

2. - El Tribunal reitera la doctrina de la sentencia de 16-11-81 (véase nuestra reseña en el número anterior de la revista), sobre el carácter equivoco del término «competencias exclusivas».

(Sentencia 5/82, de 8 de febrero; recurso 234/81 contra la Ley de la Generalidad $4 / 81$, sobre medidas urgentes sobre la función pública.)

Este Tribunal ya ha advertido, en efecto, sobre el sentido marcadamente equívoco con que el adjetivo «exclusivo» se utiliza tanto en el texto de la Constitución como en el de los Estatutos de Autonomía (sentencia de 16 de noviembre de 1981, en recurso de inconstitucionalidad núm. 184/ 1981, Boletín Oficial del Estado de 28 de noviembre de 1981, suplemento, pág. 2), $\mathrm{y}$, en consecuencia, resulta aventurado cualquier razonamiento que, como el del presente caso, intente arrancar de la diferencia existente entre una competencia atribuida con carácter exclusivo sin perjuicio de la legislación básica, que corresponde al Estado, y una competencia para legislar y ejecutar, que debe ejercerse «en el marco de la legislación básica del Estado y, en su caso, en los términos que la misma establezca». Estas diferencias de dicción autorizan a entender, entre otras consecuencias, que cuando se utiliza esta segunda fórmula se intenta sujetar más estrechamente la competencia legislativa comunitaria al marco de la legislación básica del Estado, pero en modo alguno a sostener que se ha privado con ello a la Comunidad Autónoma de su facultad de legislar hasta que sea habilitada para ello por una ley estatal, pues esto equivaldría una vez más a equiparar legislación básica con leyes matco, tesis ya rechazada explícitamente por este Tribunal.

3. La delimitación competencial de las Comunidades Autónomas no se explica tan sólo por los términos en que cada competencia se asuma en los Estatutos. Cabe, por contra, que el ámbito de esa competencia dependa de lo determinado por una ley del Estado, sea por previsión constitucional, sea por previsión del propio Estatuto.

(Sentencia 10/82, de 29 de marzo; recurso 242/81 contra Ley 6/81 de la Generalidad, reguladora del Consejo Asesor de RTVE en Cataluña.)

La norma atributiva de competencias a la Comunidad Autónoma es, pues, en principio, la norma estatutaria. Ahora bien, en ocasiones, junto a esta modalidad definidora de ámbitos competenciales, el encargo de definir competencias se condiciona en la Constitución a lo que disponga una ley, y no faltan supuestos en que el propio Estatuto restringe la asunción de competencias posibles, remitiéndose también a una ley. Este último es precisamente el supuesto del artículo 16.1 del EC, por cuanto las competencias de «desarrollo legislativo» y de «ejecución» que pudiera asumir la Generalidad «en el marco de las leyes básicas del Estado» se hizo «en 
los términos y casos establecidos en la Ley que regule el Estatuto Jurídico de la Radio y Televisión», es decir, la actual Ley 4/1980, de 10 de enero.

Por consiguiente, la Ley 4/1980 constituye el marco básico (calificado expresamente de tal, y de aplicación general en todo el territorio nacional, en su artículo 2.1) dentro del cual podrán ejercitarse las competencias autonómicas, y a la vez norma atributiva de competencia. Por la fuerza de la aludida regla del artículo 16.1 del EC, la Ley 4/1980, además de contener normas básicas, es definidora de competencias, de tal modo que en los «términos y casos» que la norma establezca podrá asumirse una competencia por la Generalidad.

4. Las Comunidades Autónomas no deben regular materias sobre las que no son competentes, aunque lo bagan reproduciendo (con matices o sin ellos) la normativa estatal.

(Sentencia 10/82, de 29 de marzo, supra, cit.)

En su sentencia de 18 de diciembre de 1981 -Boletín Oficial del Estado de 14 de enero de 1982, págs. 3 y sigs., fundamento jurídico 1, c)-, este Tribunal ya formuló reservas sobre el procedimiento consistente en reproducir ( $y$, por cierto, más o menos fielmente) normas de otras disposociones en vez de remitirse a ellas; procedimiento que, al utilizarse por órganos legislativos distintos, con ámbitos de competencia distintos, está inevitablemente llamado a engendrar tarde o temprano una innecesaria complicación normativa, cuando no confusión e inseguridad. En el presente caso no hay, evidentemente, inconstitucionalidad material, en cuanto se reiteran y particularizan preceptos del Estatuto de la Radio y la Televisión. Pero no es menos cierto que formalmente la fijación de los principios generales que han de inspirar la actividad de un órgano corresponde a quien tiene competencia para creatlo, es decir, aquí al Estado. E1 paralelismo con el artículo 4 de la Ley $4 / 81$ no es razón suficiente para salvar la constitucionalidad.

5. En relación con ello, la sentencia $5 / 82$, de 8 de febrero, indica que las bases mantienen su plena vigencia con independencia de que sean recordadas o no por el legislador comunitario, cuya referencia a ellas sólo puede revestir carácter recordatorio.

\section{B) LEGISLACION BASICA}

El Tribunal, incidiendo en su línea anterior, ha vuelto sobre la necesidad de clarificación del concepto «bases estatales». En concreto, en la sentencia 1/82, de 28 de enero (conflictos de competencia 63 y 191/81 sobre Cajas de Ahorro), agrupa sus consideraciones más conocidas sobre ello:

Es cierto, como ya se ha declarado en otros fundamentos de esta sentencia, que el Estado tiene competencia exclusiva sobre «bases», que éstas pueden estar contenidas en leyes o en disposiciones de rango inferior, que en cualquier caso las normas reguladoras de las bases pueden 
ser preconstitucionales o posteriores a la Constitución de 1978 y que en todos los casos tales normas son de vigencia general (nacional) y, por tanto, obligan a la Comunidad Autónoma del País Vasco.

Veremos de concretar ahora, de la mano de esta sentencia, tales declaraciones generales.

1.' El sentido de la legislación básica del Estado es el necesario establecimiento de una base normativa uniforme, un «común denominador normativo».

Lo que la Constitución persigue al conferir a los órganos generales del Estado la competencia exclusiva para establecer las bases de la ordenación de una materia determinada (en nuestro caso las de los núms. 11 y 13) es que tales bases tengan una regulación normativa uniforme y de vigencia en toda la nación, con lo cual se asegura, en aras de intereses generales superiores a los de cada Comunidad Autónoma, un común denominador normativo, a partir del cual cada Comunidad, en defensa del propio interés general, podrá establecer las peculiaridades que le convengan dentro del marco de competencias que la Constitución y su Estatuto le hayan atribuido sobre aquella misma materia.

2.' Se ratifica el concepto material de «bases» sentado en la sentencia de 28-7-81 sobre- Diputaciones catalanas (véase nuestra referencia en el núm. 12 de la revista).

Este Tribunal, en el fundamento $6 .^{\circ}$ de su sentencia de 28 de julio de 1981, ya ha señalado que el ejercicio de la competencia estatal para el establecimiento de las bases o legislación básica a que en distintos párrafos del apartado 1 se refiere el artículo 149 no requiere en modo alguno la promulgación de leyes de bases o de leyes marco. Así, pues, las bases a que se refieren en nuestro caso los párrafos 11 y 13 del 149.1 del $\mathrm{CE}$ no tienen nada que ver con la delegación legislativa de que tratan los artículos 82 y 83 de la Constitución ni se identifican con las leyes marco reguladas por el artículo $150.1 \ldots$

De esta noción material de bases se infiere que unas normas no son básicas por el mero hecho de estar contenidas en una ley y ser en ella calificadas como tales (lo cual sería consecuencia lógica de una noción formal de bases), sino que lo esencial del concepto de bases es su contenido.

3.' «El becho de que en una materia determinada la Constitución sólo atribuya al Estado la fijación de sus bases no significa en modo alguno que a una Comunidad determinada le corresponda ya, sin más, la regulación de todo lo que no sea básico, pues a cada Comunidad sólo le corresponderán aquellas competencias que baya asumido en su Estatuto.»

\section{Las normas básicas pueden venir determinadas por norma reglamentaria.}

Dado el carácter fundamental y general de las normas básicas, el instrumento para establecerlas con posterioridad a la Constitución es la Ley. 
Sin embargo, puede haber algunos supuestos en los que el Gobierno podrá hacer ưso de su potestad reglamentaria para regular por Real Decreto y de modo complementario alguno de los aspectos básicos de una materia determinada. Uno de tales supuestos -el único que atañe al caso que nos ocupa - se da cuando en la legislación preconstitucional (sea en leyes o en normas de rango inferior) se regulan las bases de una materia que por razón de su contenido no son incompatibles con la Constitución, y que, sin embargo, conviene complementar o adecuar a situaciones nuevas derivadas del ordenamiento constitucional como, por ejemplo, la estructura territorial del Estado. En tal supuesto, y entre tanto las Cortes Generales no procedan a establecer una regulación completa e innovadora de las bases de la materia en cuestión, el Gobierno podrá hacer uśo de un Real Decreto para cumplir la finalidad antedicha, partiendo de la legislación preconstitucional.

5. Remitiéndose a la citada Sentencia de 28-7-81, el Tribunal reitera que las Comunidades Autónomas no están obligadas a esperar la legislación básica posconstitucional, pero sí deben respetar las bases de la legislación preconstitucional.

6. El desarrollo autonómico de las bases estatales puede bacerse por Ley o Reglamento de la Cominidad.

Por otra parte, dentro de las competencias de desarrollo legislativo y ejecución conferidas al País Vasco por el artículo 11.2.a) de su Estatuto, se comprenden tanto potestades legislativas como reglamentarias, de modo que el desarrollo normativo de las bases estatales puede llevarse a cabo por Ley emanada del Parlamento vasco o, en su caso, por normas reglamentarias, cuando la naturaleza del tratamiento pueda hacerse por éstas. Desde estos postulados hay que interpretar los preceptos impugnados.

7. El concepto de legislación básica, estable por naturaleza, admite una cierta coyunturalidad.

Dado su carácter general y fundamental respecto al resto de la ordenación de la materia, las bases de la misma deben tener estabilidad, pues con ellas se atiende a aspectos más estructurales que coyunturales. Ahora bien: ciñéndonos en concreto a la ordenación de sectores económicios como el crédito, la consecución de aquellos intereses generales perseguidos por la regulación estatal de las bases del crédito exigirá que, atendiendo a circunstancias coyunturales y a objetivos de política monetaria y financiera, el Gobierno de la nación proceda a la concreción e incluso a la cuantificación de medidas contenidas en la regulación básica del crédito, pues al Gobierno de la nación le corresponden tanto la dirección de la política financiera nacional y de la política monetaria general (art. 10.26 $\mathrm{EV}$ ), en cuanto partes de la política económica general (art. 97, Comunidad Económica), como la coordinación de las mismas con las que pueda tener cada Comunidad en su ámbito respectivo (art. $45.2 \mathrm{EV}$ ).

Todo esto es compatible con la atribución a una Comunidad deter- 
minada por medio de su Estatuto del «desarrollo legislativo» de esas bases, cuya fijación es competencia del Estado, y así acontece por lo que respecta a la ordenación del crédito, banca y seguros, con el artículo 11.2.a), del Estatuto vasco. En tales supuestos es necesario tener en cuenta que el establecimiento por parte del Estado de las bases de la ordenación no puede llegar a tal grado de desarrollo que deje vacía de contenido la correlativa competencia de la Comunidad.

\section{C) DELIMITACION COMPETENCIAL EN MATERIA ECONOMICA}

En la misma Sentencia de 28-1-82, que resuelve los conflictos de competencia 63 y 191/81, el Tribunal Constitucional se enfrenta con la necesaria unidad del orden económico que se deriva de la llamada «constitución económica».

Ese marco implica la existencia de unos principios básicos del orden económico que han de aplicarse con carácter unitario, unicidad que está reiteradamente exigida por la Constitución, cuyo preámbulo garantiza la existencia de un orden económico y social justo y cuyo artículo $2 .^{\circ}$ establece un principio de unidad que se proyecta en la esfera económica por medio de diversos preceptos constitucionales tales como el 128, entendido en su totalidad; el 131.1, el 139.2 y 138.2, entre otros. Por otra parte, la Constitución fija una serie de objetivos de carácter económico cuya consecución exige la adopción de medidas de política económica aplicables, con carácter general, a todo el territorio nacional (arts. 40.1, 130.1, $131.1,138.1$ ).

Y sigue:

Esta exigencia de que el orden económico sea uno en todo el ámbito del Estado es más imperiosa en aquellos como el nuestro que tienen una estructura interna no uniforme, sino plural o compuesta desde el punto de vista de su organización territorial. La unicidad del orden económico nacional es un presupuesto necesario para que el reparto de competencias entre el Estado y las distintas Comunidades Autónomas en materias económicas no conduzca a resultados disfuncionales y desintegradores.

1. No valen, en este marco, excesos semánticos como criterio formal delimitador de los ámbitos competenciales.

Por último, no podría ampararse la presunta competencia comunitaria en tal materia en el artículo 10.25, de su Estatuto, pues si es cierto que éste otorga competencia «exclusiva» a la Comunidad en la «planificación de la actividad económica del País Vasco», también lo es que ese mismo precepto enmarca la citada competencia dentro del respeto («de acuerdo con») a la «ordenación general de la economía», y como el Estado tiene competencia «exclusiva» precisamente para las «bases y coordinación de la planificación en general de la actividad económica» (art. 14.1.13. ${ }^{\mathrm{a}}$ $\mathrm{CE})$, es claro que ambas competencias «exclusivas» están llamadas objetiva y necesariamente a ser concurrentes, de modo tal que la prioridad 
«vertical» corresponde en materia de coordinación de la planificación de la actividad económica al Estado en todo el ámbito nacional, y después, y con la obligación de someterse a aquella coordinación, ha de situarse la correspondiente competencia en la esfera comunitaria de los órganos estatutarios del País Vasco. Por consiguiente, en la medida en que la fijación del orden de prioridad controvertido afecta potencialmente a la planificación de la actividad económica, ha de insertarse por su carácter básico y general en las competencias estatales del 14.1.13. ${ }^{\mathrm{a}}$ de la $\mathrm{CE}$ y no en las del artículo 10.25 del EV.

2. Fija, en concreto, lo que se ba de entender por «bases de ordenación del crédito» (149.1.11 de la CE).

La Constitución atribuye al Estado, entre otras, la competencia exclusiva del 149.1.11, de la cual nos interesa muy en concreto lo concerniente a la fijación de las «bases de ordenación del crédito». Estas deben contener tanto las normas reguladoras de la estructura, organización interna y funciones de los diferentes intermediarios financieros como aquellas otras que regulan aspectos fundamentales de la actividad de tales intermediarios, entre los cuales se insertan legalmente las Cajas de Ahorro.

Entre la regulación de los aspectos básicos de la actividad de los distintos tipos de intermediarios financieros hay que insertar las normas concernientes al control de la cantidad de dinero bancario por su incidencia en la cantidad total de dinero existente en un momento dado en el mercado, así como también aquellas otras que imponen determinadas obligaciones a las entidades financieras privadas (Bancos y Cajas de Ahorro). Entre estas últimas se sitúan las disposiciones consistentes en fijar ciertos porcentajes o coeficientes obligatorios sobre los recursos ajenos depositados en las Cajas que deben invertir éstas en la adquisición de fondos públicos, así como también las que determinan cuáles son los valores públicos cuya adquisición por las Cajas se considera computable para cubrir el citado coeficiente de fondos públicos.

3. A tenor de ello, delimita el ámbito territorial de actuación de la institución de crédito regulada por la Comunidad.

La expansión de una Caja en un territorio ajeno al de la Comunidad donde tiene su sede social implica la absorción de recursos para luego invertirlos en parte considerable en la región donde está domiciliada.

Como este Tribunal ha afirmado ya en el fundamento segundo de su sentencia de 22 de diciembre de 1981, la consecución de los intereses de carácter supracomunitario queda confiada a los órganos del Estado, función que en materia de expansión de las Cajas de Ahorro cumple al Banco de España a tenor de la legislación vigente, a quien se le encarga actualmente de las comprobaciones necesarias para conocer o degenar la apertura de nuevas oficinas. El razonamiento expuesto nos obliga a concluir que el precepto ahora analizado invade una competencia estatal en cuanto pretende que el Departamento de Economía y Hacienda de la Comunidad Autónoma del País Vasco pueda autorizar a Cajas domiciliadas en él la apertura de oficinas fuera del mismo. 
A esta misma conclusión nos lleva, además y por otra vía, el examen del primero de los supuestos contenidos en el artículo 4.b). En efecto, con arreglo a las normas vigentes, cuyo cumplimiento pretende cristalizar la Comunidad Autónoma ésta (en lugar del Banco de España), antes de que la Caja no domiciliada en el País Vasco pudiera proceder a la apertura de oficinas situadas dentro de este territorio tendría que comprobar si tal Caja tiene «capacidad de expansión disponible», para lo cual tendría que examinar dónde la Caja tuviera su sede social, cuál es la suma de sus recursos propios según su último balance, y estaría facultada para llevar a cabo cuantas comprobaciones e inspecciones estimara necesarias para el cumplimiento de las normas reglamentarias vigentes, lo cual implicaría realizar fuera del territorio vasco unas potestades que los órganos de la Comunidad no pueden ejercer más que en el ámbito territorial del País Vasco, según se desprende en concreto del artículo 11.2.a) EV, y en términos más generales, del artículo 20.6 del mismo Estatuto.

\section{D) COMPETENCIAS AUTONOMICAS EN MATERIA DE RADIODIFUSION Y TELEVISION}

En virtud de la impugnación de la Ley de Cataluña 6/81, reguladora del Consejo Asesor de RTVE en Cataluña, el Tribunal hace una serie de importantes consideraciones sobre la competencia autonómica en esta materia (Sentencia 10/82, de 23 de marzo).

Partiendo de que el Estatuto de RTVE prevé en el ámbito comunitario tres niveles de actuación:

1) Utilización de un tercer canal propio de la Comunidad.

2) Constitución de un órgano representativo para ser oído a la hora de nombrar al delegado territorial de RTVE.

3) Regulación por ley territorial de la composición del Consejo Asesor de RTVE en la Comunidad, que asista al delegado, y nombramiento de sus miembros.

1.' A la Comunidad Autónoma corresponde desarrollar la normativa básica en el caso de la RTV propia, pero en cuanto a su participación en la RTVE queda a expensas de la ley estatal.

... diferencia de tratamiento entre la radio y la televisión propias de una Comunidad Autónoma y la gestionada por el ente público RTVE, al que competen, según el artículo $5 .^{\circ}$ de su Estatuto, «las funciones que corresponden al Estado como titular de los servicios públicos de radiodifusión y televisión».

Parece, en efecto, razonable entender que en lo que afecta a las funciones estatales ejercitadas por el ente público RTVE debe teconocerse al Estado una amplia capacidad organizativa que obligue a las Comunidades Autónomas a moverse dentro de los «términos y casos establecidos en la Ley que regule el Estatuto Jurídico de la Radio y la Televisión», reservando el solo límite de las «normas básicas del artículo 149.1.27 de la Constitución a la radiodifusión y la televisión reguladas, creadas y mantenidas por Comunidades Autónomas».

Dicho esto, es preciso añadir que la remisión del artículo 16.1 del EC, 
no puede obviamente entenderse en el sentido de que deje sin contenido la facultad de la Comunidad Autónoma de un desarrollo normativo y una ejecución de las «normas básicas», que en el presente caso están contenidas en el Estatuto de la Radio y la Televisión, regulado por la Ley 4/1980. Ahora bien: no es éste el caso, pues el Estatuto da ciertamente un margen para que dicha facultad sea efectiva en el marco que él mismo ofrece. En este margen, podrá la Comunidad Autónoma ejercer su potestad de desarrollo normativo, tanto por vía legal como reglamentaria.

2. $\quad$ No es inconstitucional que la Ley territorial desarrolle ciertos aspectos del Consejo Asesor, dada su naturaleza compleja.

Se confiere al Consejo Asesor el carácter de órgano representativo de los intereses de la Comunidad Autónoma, que lleva al seno de la organización estatal el sentir de estos intereses, lo que hace que reserve a la Comunidad Autónoma la regulación de su composición (por Ley territorial) y su nombramiento por el correspondiente órgano de gobierno). De ahí la doble vertiente de su actuación: una en cuanto órgano asesor del delegado territorial de RTVE en la Comunidad Autónoma; otra, en cuanto representante de los intereses de la Comunidad en RTVE.

Por eso:

El nombramiento lleva implícitas ciertas facultades normativas de la Comunidad Autónoma con respecto a él, en lo concerniente no al desempeño de su función, sino a su calidad de representante de sus intereses en el seno de RTVE en cuanto órgano integrador y cauce de participación, dentro del marco de la Ley 4/1980 en cuanto norma básica.

$\mathrm{Y}$ ese carácter de órgano representativo:

Da lugar a un poder de corregulación de la Comunidad en el plano organizativo, consistente en detallar y perfilar lo que la norma básica establece, es decir, dentro de los criterios básicos de la Ley 4/1980.

3. No es inconstitucional entender que el «órgano representativo» sea el propio Consejo Asesor, siempre y cuando no se pretenda con ello encubrir competencias decisorias que no puede tener.

\section{III}

\section{CONSTITUCION ECONOMICA}

La unicidad del orden económico nacional es presupuesto necesario para el reparto de competencias entre el Estado y las distintas Comunidades Autónomas.

(Sentencia número 1, de 28 de enero de 1982):

En la Constitución española de 1978, a diferencia de lo que solía ocurrir con las Constituciones liberales del siglo $\mathrm{xrx}$, y de forma semejante 
a lo que sucede en más recientes Constituciones europeas, existen varias normas destinadas a proporcionar el marco jurídico fundamental para la estructura y funcionamiento de la actividad económica; el conjunto de todas ellas compone lo que suele denominarse la constitución económica o constitución económica formal. Ese marco implica la existencia de unos principios básicos del orden económico que han de aplicarse con carácter unitario, unicidad que está reiteradamente exigida por la Constitución, cuyo preámbulo garantiza la existencia de un «orden económico y social justo», y cuyo artículo 2 establece un principio de unidad que se proyecta en la esfera económica por medio de diversos preceptos constitucionales, tales como el 128, entendido en su totalidad: el 131.1, el 139.2 y el 138.2, entre otros. Por otra parte, la Constitución fija una serie de objetivos de carácter económico cuya consecución exige la adopción de medidas de política económica aplicables, con carácter general, a todo el territorio nacional (arts. 40.1, 130.1, 131.1, 138.1).

En la sentencia dictada por el Tribunal Constitucional el 28 de enero de 1982 ante el recurso interpuesto por el Gobierno vasco en relación con el Real Decreto $2.869 / 1980$, de 30 de diciembre «por el cual se establecen las condiciones y el orden de prioridad para la compatibilidad de los valores de renta fija emitidos directamente, o calificados por las Comunidades Autónomas, en el coeficiente de fondos públicos de las Cajas de Ahorro", se formula el concepto de constitución económica como conjunto de normas destinadas a establecer el marco jurídico fundamental para la estructura y funcionamiento de toda la actividad económica. Se precisan así de forma clara cuáles son los principios que informan nuestro texto constitucional en este punto y se matiza la importancia del principio de unidad dentro de las directrices generales de la política económica, principio que es presupuesto necesario para que el reparto de competencias entre el Estado y las distintas Comunidades Autónomas en materia económica no conduzcan a efectos desintegradores.

\section{ENSEÑANZA}

La sentencia 6/1982, de 22 de febrero ( $B O E 22$ de marzo), resuelve dos conflictos positivos de competencia, los señalados con los números 211 (promovido por el Consejo Ejecutivo de la Generalitat de Cataluña) y 214 (promovido por el Gobierno vasco) de 1981, que habían sido previamente acumulados por el Tribunal Constitucional mediante Auto de 22 de septiembre de 1981 en virtud de la identidad de la norma impugnada en ambos: el Real Decreto 480/1981, de 6 de marzo (BOE 21 de marzo), sobre funcionamiento en el País Vasco y Cataluña de la Alta Inspección del Estado en materia de enseñanza no universitaria.

El motivo de fondo alegado por las respectivas representaciones de cada una de dichas Comunidades Autónomas en sus escritos dirigidos al Tribunal Constitucional es el mismo: el Real Decreto 480/1981, de 6 de marzo, regulador del funcionamiento de la Alta Inspección del Estado, invade; en beneficio de éste, el bloque de competencias en materia de enseñanza atribuidas, dentro del marco de la Constitución, a la Comunidad Autónoma Vasca en el artículo 16 de su Estatuto de Autonomía, y a la Comunidad Autónoma de Cataluña, en el artículo 15 de su Estatuto de Autonomía, puesto que dicho reglamento confiere al Estado compe- 
tencias propias no de la llamada «Alta Inspección», sino de la tradicional «inspección técnica», servicio éste que ya había sido traspasado a dichas Comunidades Autónomas en virtud de los Reales Decretos 2.808/1980 y 2.809/1980.

\section{Competencias del Estado y de las Comunidades Autónomas en materia de enseñanza}

1.1. Las competencias del Estado poseen un contenido sustancialmente normativo. Si prescindimos de la Alta Inspección, las competencias que exclusivamente corresponden al Estado en orden a la enseñanza (ordenación general del sistema educativo; fijación de las enseñanzas mínimas; regulación de las demás condiciones para obtención, expedición y homologación de títulos académicos y profesionales, y establecimiento de normas básicas para desarrollo del artículo 27 de la CE, que garanticen el cumplimiento de las obligaciones de los poderes públicos y la igualdad de todos los españoles en el ejercicio de los derechos y el desarrollo de los deberes constitucionales) tienen un contenido de carácter sustancialmente normativo, como se infiere de su propia significación semántica: «ordenar», «fijar», «regular», «establecer» son verbos que aluden a una concreción, por quien puede hacerlo, de propósitos, principios, objetivos y métodos preordenados a un fin, expresados en declaraciones de carácter imperativo.

1.2. Su ejecución puede ser atribuida a las Comunidades Autónomas. En la medida en que no se alude a los actos de gobierno y administración necesarios para hacer efectivos estos principios, desarrollarlos, aplicarlos o imponerlos, tácitamente se está admitiendo que su ejecución puede, eventualmente, ser atribuida a los poderes autonómicos, bien por disposición expresa respecto a cada uno de las facultades ejecutivas, bien porque se haga una transferencia global de todo aquello que constitucionalmente no esté reservado al Estado. Pues bien: en este caso, en cuanto a las Comunidades Autónomas vasca y catalana, porque, como se ha visto, los respectivos Estatutos les atribuyen competencia plena para la regulación y administración de la enseñanza en toda su extensión, niveles y grados, modalidades y especialidades, precisamente sin perjuicio de la «Alta Inspección».

\section{El concepto de la Alta Inspección y características de la Alta Inspección en materia de enseñanza}

Aunque el Tribunal Constitucional advierte en el texto de la sentencia sobre la dificultad de llegar a una definición conceptual de lo que sea la «Alta Inspección», sin embargo, valiéndose en parte de las coincidencias observadas entre las alegaciones de las Comunidades Autónomas que plantean el conflicto y las del abogado del Estado, y al hilo de su análisis sobre las divergencias entre ambas partes y de otras consideraciones sobre el sistema de controles del Estado respecto de las Comunidades Autónomas, ofrece una serie de claves para la delimitación de la «Alta Inspección» en materia de enseñanza.

2.1. La Alta Inspección se enmarca en el sistema de controles del Estado sobre las Comunidades Autónomas, pues éstos no se agotan èn los medios de control enunciados en la Constitución. En el Fundamento Jurídico número 7 de la sentencia, el Tribunal Constitucional, contestando la tesis sostenida por las Comunidades Autónomas demandantes, por la que el sistema constitucional de controles (el de constitucionalidad de las disposiciones normativa con fuerza de ley, art. 153 a); el de administración autonómica-por la jurisdicción contencioso-administrativa, artícu- 
lo 153 c); el control extraordinario previsto por el artículo 155; el control del artículo 161.2, que permite al Gobierno impugnar ante el Tribunal Constitucional las disposiciones y resoluciones adoptadas por los organismos de las Comunidades Autónomas, y el eventual control gubernamental, previo dictamen del Consejo de Estado, cuando la Comunidad ejerce funciones delegadas, artículo $153 \mathrm{~b}$ ), en relación con el 150.2) hace ilícitos cualesquiera otros, dice taxativamente que ese sistema de controles se ha de entender completado con aquellos otros que puedan definir los Estatutos de Autonomías y las Leyes Orgánicas, siempre que no se trate de controles genéricos e indeterminados que impliquen dependencia jerárquica de las Comunidades Autónomas respecto a la Administración del Estado, por ser éstos contrarios al principio de autonomía, tal como ya tuvo ocasión de sentar en la sentencia de 2 de febrero de 1981 (recurso 186/1980).

2.2. La Alta Inspección en materia de enseñanza prevista en la Disposición adicional 2 c) de la Ley Orgánica del Estatuto de Centros Escolares de 19 de junio de 1980 es un procedimiento lícito de control.

El Tribunal... no puede compartir la opinión de que sea necesario -ni quizá posible - un desarrollo legal futuro que establezca un contenido general de la Alta Inspección en las relaciones Estado-Comunidades; pero, respecto a una materia concreta, como es la enseñanza, la Alta Inspección, prevista en Ley Orgánica, puede ser considerada - a condición de que su posterior regulación reglamentaria no exceda esa configuración orgánica- como un procedimiento lícito de control en la segunda de las afecciones indicadas.

2.3. Características de la Alta Inspección en materia de enseñanza. De los Fundamentos Jurídicos 3, 4 y 5 de la sentencia se infieren las siguientes características:

A) La Alta Inspección en materia de enseñanza aparece revestida de un carácter jurídico ( «no sólo en lo que concierne a su ejercicio, sino en cuanto a su contenido, pues recae sobre la correcta interpretación de las normas estatales, así como de las que emanan de las asambleas comunitarias, en su indispensable interrelación»), pues es al Estado al que corresponde la garantía de la igualdad en el ejercicio del derecho a la educación y la ordenación general del sistema educativo, mediante el establecimiento de las normas básicas que garanticen el cumplimiento de las obligaciones de los poderes públicos.

B) La Alta Inspección garantiza exclusivamente el cumplimiento y garantía de aquellas facultades atribuidas al Estado, pues la educación es una materia compartida entre éste y las Comunidades Autónomas.

C) La Alta Inspección requiere y debe aceptar la colaboración con la Administración Autonómica, compatible con el respeto de las funciones legislativas, ejecutivas y garantía del propio ordenamiento autonómico.

D) No pueden confundirse los respectivos fines de «inspección técnica» y «Alta Inspección» ni duplicarse la acción administrativa de aquélla, así como tampoco vaciar de contenido, so pretexto de inspección, las competencias transferidas. Sin embargo, la Alta Inspección puede, en su caso, requerir la intervención estatal directa en los centros:

En cuanto debe discernir, como se dijo antes, las posibles disfunciones en el ámbito de las respectivas competencias del Estado y la Comunidad, lo que haría, en su caso, inconstitucional el correspondiente precepto del Real Decreto que la regula, no sería esta exigencia de actuación en los Centros sino la invasión de competencias autonómicas ejercitables en los Centros o fuera de ellos. 


\section{La titularidad de las competencias objeto de los conflictos positivos} contenidos en el Real Decreto 480/81, de 6 de marzo de 1981

En la última parte de la sentencia (Fundamentos Jurídicos 8.a.II) aborda el Tribunal Constitucional la fundamentación de su decisión sobre la titularidad de las competencias, que en todo caso ratifica en el fallo como propias del Estado, que el Real Decreto $480 / 81$, de 6 de marzo, sobre funcionamiento de la Alta Inspección del Estado en materia de enseñanza no universitaria, atribuye a éste. Los preceptos estudiados son, dado que los conflictos promovidos sólo se refieren a ellos, total y parcialmente, los artículos $2,3,5$ y 6 del aludido Real Decreto. A continuación se exponé sucintamente la doctrina del tribunal en relación con dichos preceptos, si bien previamente se reproduce el texto del artículo o de la parte del mismo controvertida, con el fin de facilitar la comprensión del lector.

Art. 2. La Alta Inspección garantizará el cumplimiento de las facultades atribuidas al Estado en materia de enseñanza en las Comunidades Autónomas, la observancia de los principios y normas constitucionales aplicables y de las leyes orgánicas que desarrollan el artículo 27 de la Constitución:

«E1 artículo 2 no vulnera tales competencias... (se refiere a las competencias de las Comunidades Autónomas vasca y catalana en materia de enseñanza)...». No las menciona. Se atiene, como acabamos de decir, al contenido constitucional estatutario y orgánico de la materia de enseñanza. Pero conviene precisar - reiterando lo que anteriormente dijimos- que, contra lo que afirma el abogado del Estado, se trata de facultades de un contenido estrictamente normativo, ya que no cabe - por vía de inspección- extender a otras competencias ejecutivas que no sean las de fiscalización del cumplimiento de los contenidos normativos (es decir, la «Alta Inspección») y las inherentes a dicha físcalización (FJ 8).

Art. 3.1. Comprobar que los planes, programas de estudio y orientaciones pedagógicas, así como los libros de texto y demás material didáctico, se adecúan a las enseñanzas mínimas y que éstas se imparten con observancia de lo dispuesto por el ordenamiento estatal sobre materias obligatorias básicas de los respectivos planes de estudio:

Respecto al número 1 del mismo se dice que implica alteración por cuanto ni los libros, ni el material didáctico, ni los planes de estudio están regulados por la Ley de Centros, ni constituyen condición para la expedición de títulos, sino que se trata de actividades propias de la inspección docente. Pero, como advierte el abogado del Estado, de lo que se trata es de comprobar si los libros y el material se adecrian a las enseñanzas minimas, pues aquéllos son medios de concretar los planes de estudio y, en cuanto a éstos, el objeto de la inspección es verificar la observancia de lo dispuesto por el Estado sobre materias obligatorias básicas (FJ 10).

Art. 3.2. Comprobar el cumplimiento de los requisitos establecidos por el Estado en la ordenación general del sistema educativo en cuanto a... los requisitos de acceso de un nivel de enseñanza a otro...

... la ordenación general del sistema educativo que corresponde al Estado (disposición adicional de la LOECE) requiere una regulación ge- 
neralizada de los niveles, según condiciones uniformes de paso de uno a otro y su comprobación, que, por cierto - como en el apartado anterior-, no requiere presencia directa en los centros, puede ser objeto de la inspección sin mengua de las competencias autonómicas (FJ 10).

Art. 3.4. Comprobar el cumplimiento de lo dispuesto por el Ministerio de Educación y Ciencia sobre las características básicas del libro de escolaridad o documentación específica que se establezca con carácter obligatorio para cada nivel de enseñanza:

Se opone al número 4... - -se refiere al escrito de la Generalidad...e insiste en el argumento de que son actividades de ejecución directa; pero la unidad del sistema educativo exige un único libro de escolaridad, ya que, de no ser así, se dificultaría la movilidad del alumnado de una a otra Comunidad Autónoma (FJ 10).

Art. 3.5. Velar por el cumplimiento... de sus derechos lingüísticos y, en particular, el de recibir enseñanza en la lengua oficial del Estado de acuerdo con las disposiciones aplicables:

... el hecho de que las autoridades del País Vasco tengan entre sus deberes el de arbitrar y regular las medidas y los medios necesarios para el conocimiento de las dos lenguas oficiales de la Comunidad (art. 6.2 del Estatuto vasco) y la Generalidad el de garantizar el uso normal y oficial de los dos idiomas, adoptar las medidas necesarias para asegurar su conocimiento y crear las condiciones que permitan alcanzar su plena igualdad en lo que se refiere a los derechos y deberes de los ciudadanos de Cataluña (Estatuto catalán, art. 3.3), no sustrae a los órganos centrales del Estado la competencia exclusiva para regular las condiciones básicas que garanticen la igualdad de todos los españoles en el ejercicio de los derecbos y en el cumplimiento de los deberes constitucionales, entre los que se encuentra el de conocer la lengua del Estado (art. 149.1.1. a, en relación con el artículo 3.1 CE)... (FJ 10).

Frente a esta tesis el magistrado Fernández Viagas (precisamente el ponente de la sentencia) formula un voto particular en el que sostiene que, por el contrario, la titularidad de la competencia a que se refiere el apartado 5 del artículo 3 del Real Decreto corresponde a las Comunidades Autónomas demandantes:

Cierto que, como se dice en la sentencia, ello no sustrae a los órganos centrales del Estado la competencia exclusiva para regular las condiciones básicas que garanticen la igualdad de todos los españoles en el ejercicio, entre otros, del derecho de conocer la lengua del Estado, pero sin que baya de bacerse invadiendo competencias autonómicas cuando -como lo bace el Real Decreto- se atribuye a la Alta Inspección la facultad no ya de comprobar, verificar o averiguar si tales condiciones se respetan, sino la de «velar» por sí misma para su cumplimiento.

Art. 3.6. Verificar la adecuación del otorgamiento de subvenciones y becas a los criterios generales que establezcan las disposiciones del Estado, así como elevar, en su caso, informes a los órganos competentes en relación con las inversiones en 
construcciones, instalaciones, equipos escolares y gastos corrientes en materia de dotaciones y retribuciones de personal:

En cuanto al número 6..., «el Consejo Ejecutivo de la Generalidad insiste en que se trata de actividad propia de inspección directa. Pero el Gobierno vasco entiende que afecta a la autonomía financiera, que corresponde a su Comunidad, y priva a su Departamento de Educación de su carácter de poder público...».

El precepto abora examinado no previene respecto a inversiones, gastos, dotaciones y retribuciones, sino meros informes que se elevarán a los «órganos competentes», es decir, se trata de una relación coordinada entre órganos estatales, que no interfiere la competencia autonómica.

Art. 5.4. Si las medidas adoptadas por el órgano competente de la Comunidad Autónoma resultasen insuficientes y persistiera la infracción, el Ministerio de Educación y Ciencia podrá, por sí mismo, poner en ejecución lo prevenido en la legislación estatal, llegando, en su caso, a privar de efectos oficiales a las enseñanzas afectadas y a denegar la expedición de los títulos correspondientes, así como a dejar sin efecto, cuando se trate de libros de texto y demás material didáctico, la autorización que tuviesen otorgada:

La constitucionalidad de este precepto sería cuestionable si se entendiese que el mismo atribuye al Estado, a través del Ministerio de Educación y Ciencia, competencias que vayan en contra de la delimitación establecida por la Constitución y los Estatutos, pero tal duda no tiene razón de ser si se lo interpreta como facultad de la Alta Inspección de comunicar la anomalía al órgano constitucional competente, a fin de que éste remedie el incumplimiento detectado mediante el ejercicio de atribuciones propias $y$ de acuerdo con los procedimientos establecidos por la Constitución y las leyes (FJ 9).

Debe tenerse en cuenta que esta interpretación adecuadora a la Constitución que el Tribunal sostiene sobre el apartado 4 del artículo 5 para evitar su nulidad, es llevada al mismo fallo de la sentencia siguiendo la técnica de la llamada «sentencia interpretativa», cuyas características básicas fueron esbozadas en el epígrafe VI de esta misma sección del núm. 13 de la revista.

Art. 6. Los funcionarios de la Alta Inspección del Estado podrán efectuar cuantas comprobaciones sean necesarias para el desempeño de sus cometidos, manteniendo en todo momento, y de modo especial cuando en el ejercicio de sus funciones precisen girar una visita de inspección, las debidas relaciones de coordinación con los órganos de la Comunidad Autónoma:'

De este artículo se limita a decir la representación de la Generalidad que supone una injerencia evidente en la función ejecutiva, que le corresponde exclusivamente, y que infringe los artículos 15 y 25.3 de su Estatuto de Autonomía. La representación del Gobierno vasco reitera la pretendida duplicidad de controles administrativos y añade que atenta a los principios de eficacia (siquiera en cuianto aumenta el gasto público), descentralización, desconcentración y coordinación explicados en el art. 103 de la Constitución.

Pero es evidente que los actos de comprobación precisos para la específica misión de la alta inspección no pueden ser actuaciones de la fun- 
ción ejecutiva autonómica, por definición, y la cita del artículo $103 \mathrm{de}$ la $\mathrm{CE}$ es irrelevante porque el atentado a esos principios generales de la acción administrativa no puede ser denunciado por vía de conflicto.

\section{$\mathrm{V}$ \\ FUNCION PUBLICA}

Nada impide a la Generalidad, siempre que respete la legislación básica del Estado, establecer a su vez, con el rango que estime adecuado, los principios a que ba de ajustarse la futura Ley de la Función Pública de Cataluña.

(Sentencia de 8 de febrero de 1982; recurso 234/1981):

Estas normas comunitarias serían constitucionalmente ilegítimas si contraviniesen las normas básicas de validez nacional, estableciendo, por ejemplo, vías de acceso a la función pública no adecuadas a los principios básicos de la legislación estatal, o aun utilizando las existentes de manera contraria a tales principios, pero nada hay en las normas pugnadas que permita tal conclusión, sin que ello, por lo más, baste para considerar sin más como constitucionalmente legítimas todas las normas que el futuro legislador comunitario pudiera dictar atendiendo a la recomendación contenida en la ley ahora impugnada.

La inexistencia de normas estätales (sobre procedimiento previo a la contratación administrativa) sólo puede ser entendida como condición de la posibilidad para que las Comunidades Autónomas que bayan asumido competencias legislativas sobre la función pública las ejerzan sin más limite que el respeto a los principios que se derivan directamente de la Constitución.

(Sentencia de 8 de febrero de 1982; recurso 234/1981):

Que en el presente caso han sido respetados, y no como prohibición implícita de que estas Comunidades Autónomas intenten regular una materia que no ha sido aún objeto de regulación estatal. En lo que toca al segundo, es obvio que la omisión en una ley particular de unas precisiones cualesquiera de carácter básico establecidas en ley general no vicia de inconstitucionalidad a aquella ley particular, pues estas precisiones mantienen su plena vigencia con independencia de que sean recordadas o no por el legislador comunitario, cuya referencia a ellas sólo este carácter de recordatorio puede revestir.

La ausencia de las normas estatales sobre la función pública, previstas en el Texto Constitucional, a juicio del Tribunal, no impide que por parte de las Comunidades Autónomas se puedan precisar cuestiones relativas a la función pública dependiente de ellas, sin que quepa tener que esperar, sobre todo cuando se trata de aspectos muy concretos (requisitos de los contratos administrativos, por ejemplo), que nada rozan con la Ley Fundamental. No ha de entenderse, en consecuencia, que la Comunidad Autónoma no pueda legislar en esta materia hasta tanto no se dicte la legislación básica prevista constitucionalmente, observación que el Tribunal ya había formulado en otras sentencias anteriores (véase sentencia de 28 de febrero de 1981). 


\section{VI \\ INDEFENSION \\ Sentencia 18-XII-1981 (rec. a. 55, 56, 57; BOE 14-I-1982)}

De la sentencia consignada extractamos los párrafos más significativos por su conexión con el título referenciado:

E1 hecho de que el proceșo de ejecución sumario se caracterice, consecuentemente con la naturaleza del título, por la ausencia de contradicción procesal, no significa que produzca indefensión y que en consecuencia resulte anticonstitucional por ser contrario al artículo 24 de la Constitución.

Lo expeditivo de la ejecución no elimina la posibilidad de contradicción, que sigue abierta en el juicio ordinario... No se limitan las posibilidades de contradecir, sino las de suspender mediante el juego de las excepciones.

Se puede afirmar que quien constituye una hipoteca se somete voluntariamente a un procedimiento con elementos de cognición limitados. Con ello no se quiere decir que la inconstitucionalidad quede eliminada por una renuncia al derecho, ya que tal renuncia no sería por sí sola suficiente para sanar el vicio..., mas no debe olvidarse que, al constituir la hipoteca, se consiente en que la defensa tenga una eficacia normativamente disminuida, por no ser apropiada para suspender la ejecución.

La sentencia razona sobre los presupuestos conocidos del procedimiento judicial sumario hipotecario. Recuérdese al respecto que la ley tipifica cuatro vías distintas para hacer efectivos los derechos derivados de la existencia de la hipoteca: ejecutiva propiamente dicha (arts. 1.429 y sigs. de la Ley de Enjuiciamiento Civil), declarativa ordinaria con arreglo a la misma ley ritual, extrajudicial (art. 129.2 de la Ley Hipotecaria) y la consistente en el procedimiento judicial sumario del artículo 131 y sigs. de la Ley Hipotecaria, que es el contemplado en la sentencia.

Algunas afirmaciones contenidas en el razonamiento del juez constitucional pueden parecer extraordinariamente delicadas si se contemplan fuera del contexto con que la doctrina ha operado para precisar el alcance procesal de dicha vía. Así se ha podido decir que existen unas notas que la individualizan perfectamente de procedimientos análogos: proceso de pura ejecución (incluso sin fase de cognición), privado del efecto típico de cosa juzgada, tramitado por fases sumarias inderogables por las partes, y compatibilidad con la discusión de fondo del conflicto en el proceso declarativo ordinario. $\mathrm{Y}$ aunque a veces se ha señalado su carácter de jurisdicción voluntaria, de suyo (Guasp) se trata de un proceso de ejecución especiál por razones jurídico-materiales. Por ello pierden objetabilidad las afirmaciones ya transcritas en el particular aspecto del sometimiento voluntario a un procedimiento con elementos «de cognición» limitados por el aceptante de una hipoteca y el consentimiento a una defensa «normativamente disminuida».

$\mathrm{Si}$ conectamos esta sentencia con la doctrina sentada en otras distintas, tenemos los siguientes criterios sobre la prohibición de indefensión:

1. Que la indefensión aparece si se actúan sólo los poderes de ejecución, pero no los de plena jurisdicción correspondientes al Poder Judicial (sentencia 26 de enero de 1981, r. a. núm. 1). Lo que en el supuesto examinado no 
ocurre, puesto que cabe el proceso de cognición ordinario diferido, como se ha dicho.

2. Que la indefensión opera si se cierra el acceso a la vía jurisdiccional (sentencia 2 de febrero de 1981, r. i. núm. 1). Lo que tampoco sucede aquí, ya que quien interviene en este procedimiento es precisamente el Poder Judicial actuando poderes ejecutivos.

3. Que la indefensión no acaece si el acceso a la prestación jurisdiccional se ejerce por vías procesales establecidas legalmente (sentencia 8 de junio de 1981 , r. a. núm. 15), cual ocurre en este supuesto, ya que se trata de un procedimiento previsto por ley formal.

4. Que la indefensión, y este criterio recapitula todos los anteriores, proscrita en el artículo 24.1 de la Constitución, debe apreciarse en cada caso, «según la naturaleza y fines de cada procedimiento», por lo que este judicial sumario es en sí mismo referencia sustantiva y suficiente para marginar el reproche de indefensión (sentencia 30 de marzo de 1981, r. a. núm. 5).

Hasta aquí hemos extractado los criterios que pueden concurrir al objeto de hacer comprensible la decisión del Tribunal en el contexto de su doctrina. Sin embargo, no podemos dejar de indicar que existen dos cuestiones que no han sido consideradas en la sentencia:

Primera: que el propio Tribunal Constitucional, en sentencia de 23 de noviembre de 1981 (r. a. 25), afirmaba algo que parece mucho más correcto, consistente en que el artículo 24 de la Constitución no «constitucionaliza todas las reglas procesales para hacer depender del cumplimiento estricto de las mismas el derecho al proceso debido». (En este caso se trataría del proceso de cognición, con plena contradicción de las partes.)

Segunda: que de haberse seguido el anterior criterio, la referencia al procedimiento judicial sumario en su tratamiento legal pierde interés por sí misma y responde más bien a una respuesta menos profunda de lo que sería de esperar, pues en ningún momento se alude por el juez constitucional a las posibles justificaciones secundum constitutionem de la existencia de semejantes procedimientos, que operan en la Ley Hipotecaria sobre una axiología (seguridad de la propiedad civil y sus derechos reales, especialmente los accesorios de garantía), absolutamente enraizada en los esquemas ideológicos de la codificación decimonónica.

\section{VII}

\section{LEGITIMACION}

Legitimación en el recurso de amparo de quien no fue parte en el proceso previo. Sentencia 4/82, de 8 de febrero (recurso de amparo num. 112/80, en suplemento al núm. 49 del «BOE» de 26 de febrero de 1982).

La legitimación para interponer recurso de amparo ante el Tribunal Constitucional está regulada en el artículo 46 de la ley del citado Tribunal, que se completa con lo establecido en los artículos 42 a 45 , inclusive, de la misma.

En el supuesto a que se refiere la sentencia que nos ocupa, la literal aplicación de lo dispuesto en los artículos 46.1.b) y 44.1.c), que le son aplicables, hubiera conducido al Tribunal a declarar no legitimado al Fondo Nacional de Garantía de Riesgos de la Circulación, en la medida en que el Fondo no fue parte en el proceso 
judicial previo. Sin embargo, el Tribunal interpreta el artículo 46.1.b) en el sentido de equiparat a los que son legitimados en el correspondiente procedimiento a los que, debiendo ser partes en un proceso, no lo fueron por causa no imputable a ellos mismos y resultaron condenados sin ser oídos, criterio que se refuerza en el presente caso en que la sentencia de casación negó al Fondo la aptitud para ser parte y mantuvo la condena al pago de la indemnización impuesta previamente sin posible rectificación, por lo que la sentencia en casación puede considerarse como el acto del órgano judicial a que se refiere el apartado $1, b$ ) del artículo 44 de la Ley Orgánica del Tribunal Constitucional:

Con carácter previo al tratamiento y solución del tema de fondo que suscita el presente recurso, se hace necesario determinar la concurrencia de la legitimación del Fondo Nacional de Garantía de Riesgos de la Circulación para su interposición y el cumplimiento del requisito del artículo 44.1.c), Ley Orgánica del Tribunal Constitucional, de cuya observancia depende su misma viabilidad, en base a su condición de presupuestos procesales en relación con la vía del amparo constitucional. En tal sentido, la legitimación de dicho organismo ha de reconocerse, en cuanto que una correcta interpretación del artículo $46.1 . b)$ de la LOTC exige la equiparación de los que, debiendo legalmente ser partes en un proceso, no lo fueron por causa no imputable a ellos mismos y resultaron condenados sin ser oídos, a los que efectivamente lo son en el correspondiente procedimiento, $y$, a mayor abundamiento, en el presente caso la sentencia dic. tada en casación, al negarle precisamente la aptitud para ser parte en la causa y mantener, por este motivo, la condena al pago de la indemnización impuesta, participa de la condición de acto del que deriva de modo «directo e inmediato» una eventual violación del derecho invocado, al haber impedido cualquier rectificación posible de la sentencia de instancia.

Recurso de amparo como cauce de pretensiones individuales directas de inconstitucionalidad.

Sentencia de 18 de diciembre de 1981 (recurso de amparo núms. 55, 56 y 57/81, suplemento núm. 12, «BOE» de 14 de enero de 1982).

El Tribunal Constitucional ha practicado una interpretación amplísima de lo dispuesto en el artículo 55.2 en relación al 41.3 de su ley rectora, pues de éstos pudiera deducirse que el planteamiento y elevación de la cuestión de inconstitucionalidad al Pleno del Tribunal quedaría reservada a las Salas del mismo, habida cuenta de que ése es el tenor literal del artículo 55.2 y que según el artículo 44.3 la pretensión en el recurso de amparo se limita al restablecimiento o preservación de derechos o libertades públicas.

Por el contrario, la interpretación que contiene la referida sentencia se concreta en admitir que en base a lo dispuesto en el artículo 55.2 la pretensión directa de inconstitucionalidad sostenida por particulares, aunque limitada a las leyes que lesionen o coarten los derechos y libertades reconocidos en los artículos 14 a 30 de la Constitución, y a los casos en que el recurrente haya experimentado una lesión concreta y actual de sus derechos y siempre que sean inescindibles el amparo constitucional y la inconstitucionalidad de la ley:

Es verdad que el apartado 3 del artículo 41 de la LOTC dice que «en el amparo constitucional no pueden hacerse valer otras pretensiones que 
las dirigidas a restablecer o preservar los derechos o libertades por razón de los cuales se formuló el recurso». Sin embargo, es también cierto que en el apartado 2 del artículo 55 se contempla el supuesto de estimación de un recurso de amparo por lesionar la ley aplicada derechos fundamentales o libertades públicas y, en este caso, permite que, elevándose al Pleno del Tribunal la cuestión, puede decidirse sobre la inconstitucionalidad de la ley. Una interpretación racional de este precepto obliga a entender que la inconstitucionalidad de la ley que lesiona derechos fundamentales y libertades públicas puede ser alegada por el recurrente del amparo. De este modo, puede admitirse una pretensión directa de inconstitucionalidad sostenida por particulares, aunque limitada a las leyes que lesionen o coarten los derechos y libertades reconocidos en los artículos 14 a 30 de la Constitución, y a los casos en que el recurrente haya experimentado una lesión concreta y actual en sus derechos y siempre que sean inescindibles el amparo constitucional y la inconstitucionalidad de la ley.

\section{VIII}

\section{LIBERTADES DE EXPRESION, REUNION Y MANIFESTACION: LIMITES}

\section{Sentencia del Tribunal Constitucional de 29 de enero de 1982 (recurso de am- paro 41/1980).}

Estas libertades no comprenden la posibilidad de ejercer una violencia moral de carácter intimidatorio por ser contraria a la dignidad de la persona y a su derecho a la integridad moral, valores constitucionales que han de respetar tanto los poderes públicos como los ciudadanos. En todo caso, cada derecho encuentra un límite en el respeto del derecho de los demás, cuyo contenido respectivo puede ser de difícil concreción en cada caso:

Pues bien: bemos de afirmar que ni la libertad de pensamiento ni el derecho de reunión y manifestación comprenden la posibilidad de ejercer sobre terceros una violencia moral de alcance intimidatorio, porque ello es contrario a bienes constitucionalmente protegidos como la dignidad de la persona y su derecho a la integridad moral (arts. 10 y 15 de la Constitución), que han de respetar no sólo los poderes públicos, sino también los ciudadanos, de acuerdo con los artículos 9 y 10 de la norma fundamental. Un límite de cada derecbo es respetar el derecho de los demás, y aunque esta delimitación de esferas pueda ser de difícil concreción en cada caso, tal dificultad no se presenta en el que es objeto de consideración, dada la claridad con que se observa que los derechos constitucionales invocados no pueden comprender actuaciones como las relatadas en los resultados de hechos probados de las sentencias impugnadas. 
IX

\section{REGIMEN ELECTORAL GENERAL}

El régimen electoral general en relación con la Constitución no afecta a las elecciones de senadores a la Comunidad Autónoma.

(Sentencia de 18 de diciembre de 1981; recurso de inconstitucionalidad 208):

Para la representación del Parlamento vasco, la identidad del régimen personal de los senadores sólo es tal una vez que unos y otros han sido elegidos o designados y no se refieren al régimen jurídico de su elección o designación; con lo cual el problema se reduce al de la competencia del Parlamento vasco para regular las inelegibilidades e incompatibilidades. A este respecto, dicha representación entiende que el «régimen electoral general», en relación con los artículos 70.1 y 81.1 de la Constitución, no afecta a las elecciones que se desarrollan en un ámbito local y que se convocan por una autoridad local y asimismo que en el caso de los senadores que corresponden a la Comunidad Autónoma no se trata de una elección, sino de una designación...

La Ley 4/1981 del Parlamento vasco, por su parte, exige para dicha designación que los candidatos tengan la condición política de vascos (art. 2.1). En este caso, el hecho de que el Estatuto de Autonomía para el País Vasco haya remitido a una ley no altera sustancialmente la situación, siempre que dicha ley se mueva dentro de los límites que resultan de una conexión con el carácter específico de su designación...

En una consideración conclusiva de conjunto de este punto cabe añadir que el tema que en el presente caso se ventila guarda la más estrecha conexión con el concepto de autonomía, el cual, con respecto a las Comunidades Autónomas, ha sido ya perfilado en anteriores sentencias de este Tribunal, por lo que no requiere ser aquí objeto de nueva valoración. Designar a los senadores de una Comunidad Autónoma en el Senado es un aspecto de la autonomía, dentro del marco de lo establecido por la Constitución (arts. 69.5 y 70.1) y por el respectivo Estatuto de Autonomía (Estatuto que en el caso vasco remite a una Ley del Parlamento vasco). Por lo demás, la «condición política de vasco» no es otra que la «vecindad administrativa, de acuerdo con las Leyes Generales del Estado», según la define el artículo 7.1 del EV, sin que el hecho de que lo sea «a los efectos del presente Estatuto» tenga para nuestro caso la consecuencia excluyente que le atribuye el abogado del Estado, ya que no es en modo alguno extraño al Estatuto, en la parte relativa a la designación, lo concerniente a los senadores de la Comunidad Autónoma.

La adecuada representación proporcional exigida sólo podrá serlo imperfectamente en el margen de una discrecionalidad que la baga flexible:

El segundo aspecto impugnado de la Ley 4/1981 del Parlamento vasco es el relativo a la «adecuada representación proporcional».

Como es sabido, la representación proporcional es la que persigue atribuir a cada partido o a cada grupo de opinión un número de mandatos en relación con su fuerza numérica. Cualesquiera que sean sus moda- 
lidades concretas, su idea fundamental es la de asegurar a cada partido político o grupo de opinión una representación, si no matemática, cuando menos sensiblemente ajustada a su importancia real. Ahora bien: es sabido, asimismo, que la proporcionalidad en la representación, difícil de alcanzar de suyo, no es tanto más cuanto menor sea el abanico de posibilidades dado por el número de puestos a cubrir en relación con el de las fuerzas concurrentes. Si ello es así en las elecciones parlamentarias o municipales, las dificultades de alcanzar la mayor proporcionalidad posible se incrementarán en elecciones internas y asambleas restrictivas que han de designar un número muy reducido de representantes, como es el caso del Parlamento vasco y en general de las asambleas legislativas o, en su defecto, de los órganos colegiados superiores de las Comunidades Autónomas. Consecuencia de ello es que la «adecuada representación proporcional» exigida sólo podrá serlo imperfectamente en el margen de una discrecionalidad que la haga flexible siempre que no altere su esencia. Será preciso, en todo caso, evitar la aplicación pura y simple de un criterio mayoritario o de mínima corrección.

En la sentencia dictada por el Tribunal Constitucional sobre el recurso de inconstitucionalidad promovido contra la Ley del Parlamento vasco de 18 de marzo de 1981 «sobre designación de senadores representantes de Euskadi», se marcan los criterios idóneos para la representación del Parlamento vasco, quedando muy preciso que el régimen electoral general que se establece en los artículos 70.1 y 81.1 del Texto Constitucional, donde se regulan las causas de inelegibilidad e incompatibilidad de los senadores y diputados y el carácter de Ley Orgánica de las normas llamadas a regular dicho tégimen, no afectan a las elecciones de ámbito local ni tampoco a los de la Comunidad Autónoma, siendo, por tanto, competencia de ésta la fijación de los criterios de designación de sus representantes en el Senado, cuestiones éstas que, según sentencia, entran dentro del ámbito de la autonomía.

De aquí que dicho recurso haya sido desestimado. 